\title{
The Impact of Gender's Variable on the Patterns and Motives of Elementary School Students in Using Social Networks: An Empirical Study on Selective Governmental Schools Jeddah, Saudi Arabia
}

\author{
Seham Ahmed Elazab ${ }^{1, *}$ \\ ${ }^{1}$ Department of Sociology \& Social Work, Faculty of Arts and Humanities -King Abdulaziz University, Jeddah, \\ Saudi Arabia \\ *Correspondence: Department of Sociology \& Social Work, Faculty of Arts and Humanities -King Abdulaziz \\ University, Jeddah, Saudi Arabia. E-mail: Selazab@kau.edu.sa
}

Received: June 9, 2016

Accepted: July 15, 2016 Online Published: August 21, 2016

doi:10.5430/wjss.v4n1p1

URL: http://dx.doi.org/10.5430/wjss.v4n1p1

\begin{abstract}
This study discusses the contents of social and psychological studies about the Patterns and Motives of Elementary School Students in using Social Networks, This study is based on" uses and gratification approach" which is instrumental in studying the impacts of communication. The study aims to search for the impact of the gender variable on (the pattern, motives, positive and negative impacts) in relation to the children in the elementary schools who are using social networks. The study relies on the descriptive concept, the demographic survey form and the questionnaire, The community of the study consisted of (254) students of both genders, the boys represent $48.8 \%$ and $51.2 \%$ girls) from public elementary schools, whom were selected from two different schools (Boys only and Girls only). The results revealed there were differences between males and females on the pattern and motives using, as to social positive/negative impacts, the males are more impacted negatively and the females impacted positively by using social networks.
\end{abstract}

Keywords: children's pattern in using social networks, children's motivations for using social networks, Positive/negative impacts in using social networks

\section{Introduction}

Social networks attracted millions of users, of all ages, all over the world. However, remarkable transformations took place in terms of style and methods of using such social networks. Moreover, social networks usage represents an important part of children's life, and this trend is supported by mobile devices that can accommodate Wi Fi capability, and it is not a secret to say some children are well acquainted with such mobile devices more than some of the parents. As a result, this study tackles the nature of using such technology, motives and impact.

Based on a report compiled in 2013, titled: Children's Usage of Mobile Devices - Global Comparison - Covering children from Algeria, Egypt, Iraq and Saudi Arabia, children in Saudi Arabia and Egypt scored the highest level of usage; in addition, $80 \%$ of children between 10-12 years of age in these countries possess mobile devises, and half of the children subjected to the research uses smart phones up to $81 \%$. As to all countries covered by the study, it was evident that children use their mobile devices for networking (Ministry of Communication \& Data Technology, 2014).

The increased networking by children in the Arab world is due to increased adult utilization of the social networks in the Middle East \& North Africa (MENA) region in 2011 as many of whom monitors news and other developments in the region; as a result, such social networks strive to launch new products as well as updating its existing services in order to attract more users within the region and worldwide.

As such social networks are part and parcel of the children's life, we have to take into consideration that such fact 
should not be omitted including the motives and related impacts regardless of the nature and motivation as well as the various impacts resulting from interacting in social networks. However, there are different point of views of various social researchers and educators regarding the pros and cons of using social networks.

In light of the foregoing, this study tackles the trends and motives that drives children to use social networks as well as the social impacts, both positive and negative, and how such changes the children's behavior, ethics and values due to communicating with various communities; subsequently, we shall employee such the positive aspects of networks interaction in appropriate educational and orientation programs, taking into account the massive capabilities of such social networks such as multimedia, video, chatting and direct communication (Mazman, \& Usluel, 2009). The aim is to transform the child from only using social networks for entertainment to utilize such capabilities in thinking, learning and interaction. Therefore, a sample of $9-12$ years old students, of both genders in the governmental schools, have to be selected for research purposes.

\section{The Study Theoretical Framework}

Firstly: Theory of Uses \& Gratifications: This study is based on uses and gratification approach which is instrumental in studying the impacts of communication means; moreover, such approach focuses on studying the audience not the research, as the audience uses such communication means based on its needs and objectives.

According to such approach, individuals are perceived as compelled by psychological, social and cultural drives to use such social networks, thus the individual is impacted by his/her social environment (Severin, and James,1992). However, Katz and others sought to develop such approach as early as the 70's of the last century whereby a number of steps determined to achieve gratifications through using multimedia. The first step is to fulfill the user's basic needs impacted by the social environment and the individual's personal traits (Brook and Dietram, 2002, p.405).

Moreover, Makkawi \& Sayed, (1998, pp: 246-247), stated that the uses and gratification theory achieves three principal objectives:

1) Enable the individual to understand how to use such communication means, relaying on the active audience who already understands how to fulfill its needs or expectations.

2) Explain the drives as to a given communication mean and the interaction involved.

3) Confirm the results of using communication means, in order to understand the mass communication process.

This approach, however, relay on a number of hypothesis as to how individuals use communication means and what they are looking for, including:

- The audience members are effective participants in mass-communication process; hence uses communication means to achieve predetermined goals.

- The use of communication means reflects the public's needs thus such use is governed by individual differences.

- The audience are themselves who chose messages and their contents that in line with their needs; therefore, the media in general compete with other resources in order to respond to audience needs.

- The audience are capable of defining their motives and needs, thus they choose appropriate media means that responds to their needs.

- We can determine the cultural standards prevailing within a community through such community's usage of such media means regardless of their contents (Makkawi \& Syed, 1998; pp: 240-241).

2.1 The Main Components of this Approach

1. SOCIAL \& PSCYCOLOGICAL ASPECTS: Numerous researchers confirmed the relationsihp between social and pscycological aspects and the exposure motives to media means which in trun define such aspects as problems that needs to be tackled (responding to needs) through social networking. However, the use of communication means depends on the individual's experience and capability in order to attain such benefits from social networks as well as applying such acquired experience in other activities within the socail participation (Fahmi, 1997; p 123)

2. MOTIVES OF USE: Both of Alfalini (1998) and Abdulraheem (2003, p 82) indicated two basic drivers for exposure to media channels, namely: 
a. Instrumental Motives - based on which the individual seeks self-understanding, attaining of knowledge and data as well as experience and learning in general which can be found in news broadcasts, educational programs and social events.

b. Ritualized Motives - where an individual tends to spend time, interacting with friends and to runaway from such problems that he/she may have, by watching immaginative films or esposeds and various entertainment topics.

However, Almusawi, (2004; p 30), established more comperehensive list for the person as to media messages, namely:

a. Congnitive Needs - connected with supporting knowledge, data and understanding the environment,

b. Effective Needs - that are related to love, friendship and excitement,

c. Social Intergratives - means social autism that aims to strenghen ties with family and friends,

d. Escapism Needs - pertaining to escaping from stress and the desire for entertainment.

3. Audience Expectations from Media: Past researches showthat uses and gratifications through communication means achieves pscycological returns that asssessed by the individuals. Hence, (Balmagrmin \& Radbern, 1985) establish the uses and gratifications based on the returns achieved or other later known as the Expectancy Value Theory, which is based on the preceiption of people as to the returns of any work they do while they assess the results differently (Makkawi \& Syed, 1998; pp: 246-247)

4. Achieved Gratifications by Using Media: Such are divided into two parts, namely:

- Content Gratifications, e.g., satisfaction from the contents navigated, thus are of two types:

a. Guidelines - represented by attaining such information and data, self-affirmation and environment monitoring,

b. Social - Users connect such data with what they have and what social networks offer,

- Practical - users communicate with one media to attain certain data, hence such is of two types:

a. Guidelines - achieved through stress and self-defense,

b. Quasi-Social - achieved by introvert individuals or those who lacks wide social relations through communicating with others to cope with loneliness or isolation from others (Wenner, 1985)

Therefore, this approach is appropriate to research the recent study in order to understand how children respond to such large value of information and data through social networks, and also to better determine the audience' social aspects, media usage, consistency as well as précised understanding of timing. The demographic data of users helps the research to go deeper by testing behavior, actions and reactions of the user. As a result, this study shall tackle the patterns, motivations and impacts on such users, namely students in elementary schools.

Secondly: Social Networks Usage Pattern: In fact, we attained ample knowledge and references from such previous social science studies that tackled the subject of social networks and their various impacts on users. Nonetheless, this study focuses on 1) the age, e.g., 6-12 years where previous studies focused on the teenage and youth milestones, 2) the sub-dimensions of usage pattern and the time spent on social networks, most favorable communication patters, acceptance or rejection of friendship requests, the relationship of the child user's with the person who helps him/her initiate an account on the internet, e.g., parents who also monitor their child activity on the internet, 3) pattern, motives and impact of internet usage taking into consideration some family demographic variables. In short, this study endeavors to tackle such area not covered by previous studies on this subject; moreover, focuses on the gender variable.

By assessing the results of previous studies, e.g., patterns, indicators, parents' consent involvement, it is clear that different parents have different positive/negative perceptions as to their children use of communication channels (Michele et al., 2014). Moreover, while some of the previous studies indicated that children usually interact in the internet at the age of 9 and most parents are aware of such involvement, other studies pretend that younger children hesitate to interact with their parents on social networks, and that $40 \%$ of the students prefer not to be friends with their parents on social networks (Simonpietri Stacie, 2011). Moreover, other studies say that most parents do not have the skills of early training for their children prior to using social networks (Shalynn \& Bethany, 2013).

As to the most preferable social networks among users, many studies suggest that Facebook and U-Tube ranks first. However, the study conducted by (El Khouli, 2013) indicated that U-Tube is the most channel used by families in the 
United Arab Emirates, followed by Facebook. Other studies say that $59.59 \%$ of users uses at least one social network for communicating with friends, and that Facebook comes first for $83 \%$ of users. However, there are not usage and pattern differences among both genders (Michele et al., 2014). where the study conducted by (Jarar, 2011) indicated that $74.4 \%$ of Jordanians have accounts on Facebook, $56 \%$ of which are males and $44 \%$ females. As to pattern differences, the study conducted by (Muise et al., 2009) indicated that females of the same sample are more than males on Facebook.

As to the time spent daily on social networks, results suggest that 1 to less than 3 hours a day, hence evening time represent the peek for users (Elazab and Alghamdei, 2011), where other study conducted by (Sha'alan, 2013) suggested that 4-6 hours a day is spent by the user, where (Jarar, 2011) indicated that 73.8 drop by social networks daily. However, the study conducted by Ktas et al. (2014) stated that $68 \%$ of students use social networks daily, $39 \%$ of which were females - and by this fact we can see the gender factor and the time of using social networks, and that males spent more time than females, e.g., 5-6+ hours a day and 2-3 hours or 3-4 hours a day for females. Nonetheless, the study conducted by (Titto \& Nivedhitha, 2014) found that the use pattern depends on those who have access to the internet at home and those who doesn't, and that most students spend 2+ hours a day with mild difference between males and female as to the number of visiting social networks, e.g., $32 \%$ of females visit social networks more than one time a day vs. $30 \%$ of males and there isn't differences in the pattern among both genders.

As to the most favored topics, some studies suggest that $76.5 \%$ of users tend to navigate through friends' pictures/photographs (Khader, 2009), hence this is in line with the study conducted by Simonpietri Stacie (2011), which also stated that SMS are favored more than communicating with parents via social networks, and that only $5.75 \%$ communicate with their parents via Facebook, and that $50-100 \%$ of such students spend most of the time monitoring, searching photographs, updating, messaging and posting their views on Facebook. However, the study conducted by (Michele et al., 2014) stated that nearly 50\% of teenagers communicate daily with friends using SMS in addition to other communication means including social networks.

As to acceptance of friendship requests, some fears interacting with strangers (O'Keeffe, 2011 and Lenhart \& Madden, 2007) and some show positive attitude (Ktas et al., 2014 ), which stated that both parties reacted positively for friendship. Moreover, both genders believe that Facebook contributed significantly as to widening the circles of friendship and simplified communications among friends. In addition, some believe that those who use Facebook are more known and important people. As to privacy, males tend to know more about their friends than females and this is in line with the study conducted by Quinn and Oldmeadow (2013), which stated that friendship among groups in the social networks is strong.

Thirdly: Motives of Using Social Networks: The social networks use motives were classified by Huang (2011) as: Social, informational and entertainment satisfaction; thus, entertainment usually leads to addiction and the informational is the least for addiction. However, Sha'alan (2012) stated that children and youths resort to social networks for popularity and self-introduction and to compensate for such failures they encounter in real life. Such conclusions are in line with O'Keeffe (2011) findings that the majority of teenagers maintains communication with friends or attaining new friendships through social networks. However, Alazab \& Alghamdi (2011), indicated that amusement, spending time and searching for friendships were the most motives for both genders using social networks, and most of the users have relative relationships or common interests, and such conclusions are in line with Wijesundara (2014) that confirms amusement within the American youths is the prime motive for using social networks, and this also in line with the study conducted by Khader (2009) indicated that both genders agree that development of personal skills, life experience, interacting with others and communicating with friends are prime motives.

Fourthly: Impacts of using Social Networks: As to the positive impacts, the study conducted by Alzayoun \& Awdah (2014) indicated that females are positively impacted socially and culturally by social networks more than males, where males are impacted negatively socially and culturally more than females. However, the study conducted by Alzayoun \& Awdah (2014) stated that social networks impacted more the researchers through improving the language and opinion communication, and this is in line with the results of the study conducted by Abdulrahman (2011) which confirms that electronic means enabled the child to learn more about his/her religious culture as well as the social aspect by widening the circles of friendship as well as expanding the family dialogue. Moreover, the study conducted by Quinn and Oldmeadow (2013) show that there is a consistent relationship between excessive usage of social networks and strong belonging as to males more than females.

As to the negative impacts, the study conducted by Alzayat (2011) indicated that social networks impacted the females negatively as some of them were cheated by other users, in addition to negative health issues. However, the 
study conducted by Sha'alan (2012) show that social networks have contributed to more indiscipline and social detachment within the family as well as negative manners that contradicts with the family norms; hence, this is in line with the study conducted by Meier (2015), which confirms both negative and positive impacts on children as to identity. In addition, the study conducted by Abdulrahman (2011) confirms that children are misusing and abusing social networks thus lead to improper behavior, and that children became more isolated by parents abandoning them to be alone to themselves. However, the study conducted by Jarar (2011) confirmed that $57.4 \%$ of social networks users believe that spending time on the internet has taken the time that should be spent with families, moreover, the study conducted by El Khouli (2013) show that teenagers uses negatively the social networks, and such conclusion is in line with the (Titto \& Nivedhitha 2014) conclusion, e.g., the more time the child spends on the internet the less time he/she communicates with family.

\section{The Study Objective}

The current study aims to understand the impact of the gender variable on: The pattern, motives, positive and negative impacts, in relation to children in elementary schools who uses social networks.

\subsection{Sub-objectives}

1. To determine the differences of children's pattern, both genders, in using social networks,

2. To determine the differences of children's motivations, both genders, for using social networks,

3. To determine the differences of children's cultural positive/negative impacts, both genders, in using social networks.

\subsection{The Study Questions}

1. Are there differences among the children's patterns, both genders, in using social networks? Such question poses sub-questions as to patterns, including:

a. Are there differences in the kinship of the child and the person who establish an account for the child in order to log into social networks?

b. Are there differences among the children as preferences for social networks?

c. Are there differences among the children as to the time spent on social networks?

d. Are there differences among the children as to the preferred times for visiting social networks?

e. Are there differences among the children as to the types of interactions on social networks?

f. Are there differences among the children as to accepting friendship requests from strangers on social networks?

2. Are there differences among the children's motives, both genders, in using social networks?

3. Are there differences among the children's positive and negative impacts, both genders, in using social networks?

\subsection{The Study Limitations}

Time : The study conducted during the period March-April of school year 2005/2006.

Place : Jeddah, Saudi Arabia. A selective sample was chosen from two public schools, namely Prince Sultan School (boys), and the $23^{\text {rd }}$ Elementary School (Girls).

Population: A sample of 254 students, $3^{\text {rd }}-6^{\text {th }}$ grades (9-12 years old) who uses social networks.

\subsection{The Study Methodology}

Type of this Study: This is a descriptive study which aims to collects such facts and data related to a given subject, interpretation of such data in terms of quantity and quality and to understand the phenomenon's relationship with counterparts (Obaidat et al., 2014, p 107). The researcher adapted the social survey concept for the sample, and conducted interviews as well as a questionnaire to answer such questions related to the study in order to determine such differences among the students taking into consideration the gender.

Community \& Sample: The community of the study consisted of 254 students of both genders, the boys represent $48.8 \%$ and $51.2 \%$ girls) from public elementary schools, who were selected from two different schools (Boys only and Girls only). The researcher was aided by a supervisor from each school to collect such data required.

The Tools Used: A questionnaire was used which was designed by the researcher, depicting 4 main sections: 
- The first section consist of ( 6 ) totally or partially closed questions about the use patterns,

- The second section consist of ( 7 ) questions about motives in using social networks,

- The third section consist of ( 14 ) questions to measure positive impacts,

- The fourth section consist of ( 12 ) questions to measure negative impacts,

Validity and Reliability: The researcher employed a number of steps to Validity and Reliability:

Firstly, the questionnaires collected and presented to a panel of sociologists, psychologists and socio-statisticians in order to verify the relevance of such questions to the ages of such children formed the sample, phrasing, clarity and simplicity, and the objectives to be achieved from such questionnaires. Accordingly, the panel approved $80 \%$ of the questionnaire's contents, and eliminated certain questions and phrases and re-phrased appropriately.

Secondly, Validity of the internal consistency for the third and fourth sections (positive/negative impacts) through correlation coefficient and the total scores based on the connection of the four sections of the questionnaire, which was at 0.176 , which means the more positive impacts' scores the negative impacts becomes lesser and vice versa, which confirms credibility of the total scores of questionnaires' main and sub components. The following Table 1 reflects the internal consistency of positive/negative social impacts.

Table 1. Internal Consistency of Positive/Negative Social Impacts

\begin{tabular}{ccccccc}
\hline Impacts & Phrase No & $\begin{array}{c}\text { Correlation } \\
\text { Coefficient as to } \\
\text { the value }\end{array}$ & Phrase No & $\begin{array}{c}\text { Correlation } \\
\text { Coefficient as to } \\
\text { the value }\end{array}$ & $\begin{array}{c}\text { Correlation } \\
\text { Phrase } \\
\text { No }\end{array}$ & $\begin{array}{c}\text { Coefficient as to the } \\
\text { value }\end{array}$ \\
\hline & 1 & $.405^{* *}$ & 6 & $.166^{* *}$ & 11 & $.343^{* *}$ \\
Positive & 2 & $.534^{* *}$ & 7 & $.394^{* *}$ & 12 & $.574^{* *}$ \\
Social & 3 & $.530^{* *}$ & 8 & $.329^{* *}$ & 14 & $.551^{* *}$ \\
Impacts & 4 & $.420^{* *}$ & 9 & $.341^{* *}$ & 14 & $.161^{* *}$ \\
& 5 & $.490^{* *}$ & 10 & $.509^{* *}$ & & \\
\hline & 1 & 102 & 5 & $407^{* *}$ & 9 & $613^{* *}$ \\
Negative & 2 & $.195^{* *}$ & 6 & $.672^{* *}$ & 10 & $.576^{* *}$ \\
Social & 3 & $.441^{* *}$ & 7 & $.489^{* *}$ & 11 & $.529^{* *}$ \\
Impacts & 4 & $.488^{* *}$ & 8 & $.581^{* *}$ & 12 & $.425^{* *}$ \\
\hline
\end{tabular}

** Sig. (0.01)

Thirdly, by using 'Coronbach's Alpha', the Reliability for positive social impacts were at 0.619 , and the negative social impacts were at 0.667 ; hence, such is acceptable statistically.

\subsection{The Study Variables}

a. The independent variable: Gender ( male/female)

b. The dependent variables (pattern, motivations, positive/negative impacts of using social networks.

Statistical Methods: For the purpose of this study, the researcher used a number of steps to ensure credibility and consistency, including correlation coefficients, Coronbach's Alpha, Chi Square Test $\chi^{2}$ depending on the gender's variable.

The study results and interpretation: The study, as indicated earlier, is to answer a set of questions, and the statistical analysis revealed the following results:

Question one result: Are there differences among children of both genders in the pattern of using social networks?

a. Are there differences in the kinship of the child and the person who establish an account for the child in order to log into social networks? 
Table 2. Males/Females Differences - Relationship of the Person Who Sets the Account

\begin{tabular}{ccccccc}
\hline & \multicolumn{2}{c}{ Males } & \multicolumn{2}{c}{ Females } & & \multirow{2}{*}{ Sig. } \\
\cline { 2 - 5 } Relationship & $\mathrm{F}$ & $\mathbf{\%}$ & $\mathrm{F}$ & $\mathbf{\%}$ & $\chi^{2}$ & 0.01 \\
\hline Created by myself & 53 & 42.7 & 21 & 16.2 & 13.83 & - \\
Created by parent(s) & 34 & 27.4 & 26 & 20.0 & 1.06 & 0.01 \\
Created by a brother & 21 & 16.9 & 70 & 53.8 & 26.38 & - \\
Created by a relative & 8 & 6.5 & 13 & 10.0 & 1.19 & - \\
Created by a friend & 8 & 6.5 & 0 & 0 & - & \\
\hline TOTAL & 124 & 100.0 & 130 & 100.0 & & \\
\hline
\end{tabular}

It is clear from Table 2, the males $42.7 \%$ more than females $16.2 \%$ in setting up social networks accounts. The Chi-square value was 13.83 and Significant 0.01 , and according to the gender variable the males comes first.

However, females depended in their brothers for creating the account, at $53.8 \%$ vs. $16.9 \%$ for males. The Chi-square value was 26.38 and Significant 0.01, which means there is difference on depending on a brother according to the gender variable the females comes first.

Nonetheless, there weren't differences among males and females in depending on one of the parents or a relative and there weren't a sample of female dependence on a friend as to the variable of females.

In short, males relayed more on themselves, and the females sought the help of brothers; thus, such result is in line with some studies such as Stacie Simonpietri (2011) that claims younger generations aren't interested to interact with their parents on social networks, also (Shalynn \& Bethany, 2013) that stated most parents are not skilled enough as to social networks, where the study of (Michael, 2013) disagree with such conclusion that parents in general are communicating with their children on social networks.

In other words, the results of this study show that male children tend to be independent and are skilled in using social networks. The females, however, seem to be under rigid monitoring by parents and therefore they resort to one of the brothers to create a social network account. As the results of this study shows there is not differences between both genders in the creation of social networks accounts by a friend, this can be attributed to the rigid monitoring of the parents in such age as well as the co-education is not available in Saudi Arabia thus males and females are separated.

b. Are there differences among the children as preferences for social networks?

Table 3. Males/Females Differences - Most Social Networks Preferred

\begin{tabular}{ccccccc}
\hline Most Preferred & \multicolumn{2}{c}{ Males } & \multicolumn{2}{c}{ Females } & & \multirow{2}{*}{ Sig. } \\
\cline { 2 - 5 } Social Networks & $\mathrm{F}$ & $\mathbf{\%}$ & $\mathrm{F}$ & $\mathbf{\%}$ & $\chi^{2}$ & - \\
\hline Instegram & 50 & 40.3 & 49 & 37.7 & 0.01 & - \\
Tweeter & 11 & 8.9 & 19 & 14.6 & 2.13 & - \\
Snap-Shot & 15 & 12.1 & 20 & 15.4 & 0.71 & - \\
Facebook & 6 & 4.8 & 10 & 7.7 & 1.02 & 0.05 \\
U-Tube & 35 & 28.2 & 21 & 16.2 & 3.50 & - \\
Others - remember & 7 & 5.6 & 11 & 8.5 & 0.88 & \\
\hline TOTAL & 124 & 100.0 & 130 & 100.0 & & \\
\hline
\end{tabular}

Table 3, however, reflects that the males $28.2 \%$ vs. females $16.2 \%$ for using U-Tub. The Chi-square value was 3.50 and Significant 0.05, which means there are differences based on the gender variable, for males.

Such result is in line with the study conducted by (El Khouli, 2013) disagreed with such conclusion saying that Facebook is the most preferred for most of the users and that there are not differences between both genders as to the pattern. Moreover, the study conducted by Muise et al., (2009) stated that females are the most exposed to social networks more than the males. Nonetheless, the study conducted by Mansour (2014) revealed there is a relative decline in both genders as to using Tweeter, and that the differences were for males as to Facebook and Google plus for females. 
This result can be attributed to the expanding of such networks and easy-to-use as well as availability of ample video products that fits the children aims in terms of entertainment. Such fact is confirmed by the theory of uses and gratification, which says personal and cultural aspects, influences pubic norms as to using the media.

c. Are there differences among the children as to the time spent on social networks?

Table 4. Males/Females Differences - Time Spent on Social Networks

\begin{tabular}{ccccccc}
\hline Daily Time & \multicolumn{2}{c}{ Males } & \multicolumn{2}{c}{ Females } & & \\
\cline { 2 - 5 } Spent on Networks & F & $\mathbf{\%}$ & F & \% & $\chi^{2}$ & Sig. \\
\hline Less than 3 hours & 73 & 58.9 & 52 & 40.0 & 3.528 & 0.05 \\
3 to 6 hours & 24 & 19.4 & 32 & 24.6 & 1.143 & - \\
More than 6 hours & 27 & 21.8 & 46 & 35.4 & 4.945 & 0.01 \\
\hline TOTAL & 124 & 100.0 & 130 & 100.0 & & \\
\hline
\end{tabular}

It is clear from Table 4, as to such children uses the internet for less than 3 hours, where males counts for $58.9 \% v s$. females $40.0 \%$ as to the time spent on social networks. The Chi-square value was 3.528 and Significant 0.05 , which means there are differences based on the gender variable for males.

It is also conspicuous that females are increased users, e.g., more than 6 hours/day, where males represent $21.8 \% v s$. $35.4 \%$ for females. Thus, The Chi-square value was 4.945 , at 0.01 which indicates differences in the time spent on social networks as per the gender's variable for the females.

Moreover, the statistical indicator show that the use of social networks among males and females ranges between 3 to 6 hours a day.

This result, in general, is in line with Alazab \& Alghamdi (2011), which indicated that usage ranges between 1 to less than 3 hours a day, as well as Sha'alan (2012), that indicted less than 4 to 6 hours a day, and Jarar (2011) that claimed $75 \%$ of users who represent $73.8 \%$ visit such social networks on daily basis, and finally (Mansour, 2014) that indicated there are differences among males and females as to the number of hours spent on social networks.

However, the study conducted by Ktas et al., (2014) differs by saying that males spent longer time than females on social networks, e.g., 5 to 6 hours and more, where females spends 1-2 hours or 3-4 hours a day. Also, (Titto \& Nivedhitha, 2014) indicated that there is a difference in the patterns of using social networks.

Hence, such result can be attributed to the social structure of the research community and the social norms that dictates the behavior based on such social culture prevailing. Therefore, the community of this study are living in such very conservative society thus are controlled by family rules as well as social barriers, and accordingly they pursue every way in order to fulfill their basic needs that are in line with the social structure as well as the personal traits.

d. Are there differences among the children as to the preferred times for visiting social networks?

Table 5. Males/Females Differences - Time preference on Social Networks

\begin{tabular}{ccccccc}
\hline & \multicolumn{2}{c}{ Males } & \multicolumn{2}{c}{ Females } & & \\
\cline { 2 - 5 } Preferred Time & F & $\mathbf{\%}$ & F & \% & $\chi^{2}$ & Sig. \\
\hline During Week Days & 79 & 63.7 & 56 & 43.1 & 3.91 & 0.05 \\
During Weekends & 45 & 36.3 & 74 & 56.9 & 7.06 & 0.01 \\
\hline TOTAL & 124 & 100.0 & 130 & 100.0 & & \\
\hline
\end{tabular}

Table 5, above show that males increasing number uses social networks throughout the week, representing $63.7 \%$ vs. $43.1 \%$ females, The Chi-square value 3.91 and Significant 0.05 , which indicates differences in the preferred times thus the males prevail.

Moreover, it is clear the increased number of social networks users during weekend, hence the females surpasses males, e.g., 56.9\% females vs. 36.3\% males, The Chi-square value 7.06 and Significant 0.01, which indicates differences in the preferred times thus the females are placed first. 
As we indicated earlier, such result is due to increased freedom and low control over the males in comparison to females who also connected more with parents than males thus are under more monitoring and control. These conclusions are confirmed by the theory of uses and gratification, e.g., the public is active in mass media and uses such channels to satisfy their expectations and needs, hence the individual's differences controls patterns and uses of social networks.

e. Are there differences among the children as to the kind of interactions on social networks?

Table 6. Males/Females Differences - Interaction Preferences on Social Networks

\begin{tabular}{cccccccc}
\hline \multirow{2}{*}{ kind of Interactions } & \multicolumn{2}{c}{ Males } & \multicolumn{2}{c}{ Females } & & \\
\cline { 2 - 5 } Chatting & $\mathrm{f}$ & $\mathbf{\%}$ & $\mathrm{F}$ & $\mathbf{\%}$ & & Sig. \\
\hline Audio/Video Chatting & 27 & 21.8 & 45 & 34.6 & 4.50 & 0.05 \\
Exchanging photo \& video clips & 20 & 16.1 & 9 & 6.9 & 4.17 & 0.05 \\
Exchanging various photos and video & 18 & 14.5 & 40 & 30.8 & 8.34 & 0.01 \\
All of the above & 48 & 38.9 & 8 & 6.2 & 0.47 & - \\
\hline TOTAL & 124 & 100.0 & 130 & 100.0 & & \\
\hline
\end{tabular}

Table 6 that females prefer audio chatting, representing 34.6\% vs. $21.8 \%$ males, The Chi-square value 4.50 and Significant 0.05 , which indicates differences in the preferred times thus the females takes first place.

As to exchanging of photos and video clips, females represent $30.8 \%$ and $14.5 \%$ males, the Chi-square value 8.34 and Significant 0.01, which indicates differences the females takes precedents. However, such result is in line with Khader (2009), who confirmed most users tend to prefer exchanging of friends' photos, as well as Stacie Simonpietri (2011) SMS are the most preferred than social networks.

As we indicated earlier, such result is due to increased freedom and low control over the males in comparison to females who also connected more with parents than males thus are under more monitoring and control. These conclusions are confirmed by the theory of uses and gratification, e.g., the public is active in mass media and uses such channels to satisfy their expectations and needs, hence the individual's differences controls patterns and uses of social networks.

Hence, it was found that users who prefers audio/video chatting, the males represents $16.1 \% v s .6 .9 \%$ for females, The Chi-square value 4.17 and Significant 0.05 . As to using all aspects of networks, $38.7 \%$ males $v$ s. $21.5 \%$ for females, The Chi-square value 5.26, and Significant 0.05, which indicates differences in the scope of using networks. Such result, however, is in line with the study conducted by Michele et al., (2014), which confirmed that 50\% of teenagers use SMS for communicating with friends, in addition to social networks and media channels.

Nonetheless, there weren't differences statistically among males and females as to exchanging various photos and video clips on social networks.

f. Are there differences among the children as to accepting friendship requests from strangers on social networks?

Table 7. Males/Females Differences - Accepting Friendship Requests from Strangers.

\begin{tabular}{ccccccc}
\hline & \multicolumn{2}{c}{ Males } & \multicolumn{2}{c}{ Females } & & \multirow{2}{*}{ Sig. } \\
\cline { 2 - 6 } Requests Acceptance & $\mathrm{f}$ & $\mathbf{\%}$ & $\mathrm{F}$ & $\mathbf{\%}$ & $\chi^{2}$ & - \\
\hline YES & 51 & 41.1 & 58 & 44.6 & 0.450 & - \\
NO & 73 & 58.9 & 72 & 55.4 & 0.007 & - \\
\hline TOTAL & 124 & 100.0 & 130 & 100.0 & & \\
\hline
\end{tabular}

As show in Table 7, there are differences among males and as to accepting/rejecting friendship requests from strangers.

However, such result is in line with a number of previous studies that confirmed various reactions by users as to accepting friendship requests: Fear from strangers 23\% according to the study conducted by O'Keeffe (2011) or 
those who feel positive towards new friendships (Ktas et al., 2014), where Lenhart \& Madden (2007) stated that $23 \%$ of users felt paranoid towards accepting strangers among their friends.

However, other studies such as: Ktas et al., (2014) which indicated that males on social networks seek friendship more than females, as well as, Ktas et al. (2014) which came up with the same conclusion.

2. Are there differences among the children's motives, both genders, in using social networks?

Table 8. Males/Females Differences - Motives for Using Social Networks

\begin{tabular}{|c|c|c|c|c|c|c|}
\hline \multirow[b]{2}{*}{ Motives } & \multicolumn{2}{|c|}{ Males } & \multicolumn{2}{|c|}{ Females } & \multirow[b]{2}{*}{$\chi^{2}$} & \multirow[b]{2}{*}{ Sig. } \\
\hline & $\mathrm{f}$ & $\%$ & $\mathrm{~F}$ & $\%$ & & \\
\hline Self-Introduction & 21 & 16.9 & 10 & 7.7 & 3.9 & 0.05 \\
\hline Entertainment/Time-Killing & 49 & 39.5 & 29 & 22.3 & 5.1 & 0.05 \\
\hline Communicate with family/friends & 23 & 18.5 & 40 & 30.8 & 4.5 & 0.05 \\
\hline Finding New Friendships & 11 & 8.9 & 1 & 0.8 & 8.3 & 0.01 \\
\hline Celebrities/Fashion News & 9 & 7.3 & 36 & 27.7 & 16.2 & 0.01 \\
\hline Monitoring Developments & 11 & 8.9 & 14 & 10.8 & 0.36 & - \\
\hline
\end{tabular}

As reflected in Table 8, above, males interested in self-introduction represent $16.9 \%$ vs. $7.7 \%$ females, The Chi-square value 3.9 and Significant 0.05 which means there are differences as to males; as to entertainment and time-killing, the males represent $39.5 \%$ vs. $22.3 \%$ females, the Chi-square value was 5.1 and Significant was 0.05 , and those who look for new friendship the males takes precedence; as to Finding New Friendships, the males represent $0.9 \%$ vs. $0.8 \%$ females, The Chi-square value 8.3 and Significant 0.01 which means there are differences as to males. This result, however, is in line with Sha'alan (2012), which indicates that most children seeks new friendships; nonetheless, entertainment is the most motive among youths (Wijesundara, 2014) as well as self-introduction. Furthermore, O'Keeffe (2011) indicated that most of the youths use social networks to maintain communication with friends and to form new friendships.

The motive for child females, however, is to maintain communication with family and friends, thus representing $30.8 \%$ vs. $18.5 \%$ males, the Chi-square value 4.5 and Significant was 0.05 , which means females are placed first. As to monitoring celebrities and fashion, the females represent $27.7 \%$ vs. $7.3 \%$, the Chi-square value was 16.2 and Significant was 0.01. such result concurs with the study conducted by Alazab \& Alghamdi (2011), that confirmed the motives of entertainment, time-killing and seeking new friendships were the most. However, Khader (2009) indicated that communicating with family and friends is most favored through Facebook.

As to monitoring new developments on social networks, there were not differences, and this conclusion is in line with (Huang, 2011) which confirmed that entertainment satisfaction takes precedence thus is possible addiction where seeking information is less probable for addiction.

These findings, in general, and according to the theory of uses and gratifications, that self-introduction, entertainment, time-killing and seeking new friendships are the primary motives within males children of such age. However, communication with family and friends and monitoring of celebrities and fashion are the motives for females. As to monitoring latest developments, both genders have no interest in such topics, which means personal, emotional, social seeking knowledge motives were dominant among both genders related to this study.

As mentioned earlier, such result is due to the environment and social limitations that grants the males more freedom then females, thus, it is clear that males interacts with and maintains friendship with strangers where the females convey themselves to family and immediate friendships with their families. In addition, males are raised up to take the lead as the 'tough-man' where the females are taught to obey, agree and be concerned with social maters and beauty. These facts are evident by the preferences of each gender as indicated herein.

3. Are there differences among the children's positive and negative impacts, both genders, in using social networks?

To answer this question, the researcher used the "Independent Samples " $t-T e s t$ " formula: 
Table 9. Males/Females Differences - Positive/Negative Impacts of Using Social Networks.

\begin{tabular}{lcccccc}
\hline & Gender & $\mathbf{N}$ & Mean & Std. Dev. & T & Sig. \\
\cline { 2 - 7 } & Males & 124 & 28.63 & 4.48 & 2.63 & 0.05 \\
Social Negative Impacts & Females & 130 & 27.00 & 5.34 & & \\
\hline \multirow{2}{*}{ Social Negative Impacts } & Males & 124 & 24.87 & 4.53 & 2.42 & 0.05 \\
& Females & 130 & 26.53 & 5.13 & & \\
\hline
\end{tabular}

The T-Test results, as shown in Table 9 above, shows the meals represent 28.63 and the females 27.0, which means males are more impacted negatively than females. However, such result is in line with Sha'alan (2012), Jarar (2011) and Titto \& Nivedhitha (2014) who confirmed that social networks contributed to less discipline as well as acquiring bad habits, and that half of youths believes that social networks have lessen the time that they spend with their families. Moreover, the study conducted by (El Khouli, 2013) concluded that teenagers are using social networks for negative endeavors more than others.

As to the social positive impacts, as per the T-Test results 42.2, and the mark 0.05 , where the females represent 26.35 , which is higher than the males 24.87. such result is in line with Alzayat (2011), which stated that the females impacted positively by social networks, e.g., development of skills and improving reading and writing and friendship circles worldwide, Abdulrahman (2011) that concluded social networks contributed to more understanding of the religious culture, and (Quinn and Oldmeadow, 2013) Which indicated that negative social and cultural impacts are more with males than females, and (Meier, 2015) which confirmed that social networks impacted the children's identity positively and negatively.

Such result can be attributed to the fact that social networks were instrumental for females who found the opportunity to communicate with wider circles including family and friends without fearing direct contact which is forbidden by social rules within the Saudi community where the males have greater margin for movement, involvement and interaction. Also, the Expectancy Value Theory which says that people act thus anticipating special returns therefore people are compelled by such expectations through social networks an media.

\section{Summary \& Conclusions}

1. As to patterns of using social networks by males and females, the results were as follows:

a. There were differences between males and females who initiate their own accounts by themselves, and the males mostly initiate such accounts without help, where females resorted to a brother (neither a parent nor a relative or a friend) to set up the accounts.

b. There were difference between males and females as to preferring U-Tube, thus the males takes the lead. As to preferences in using other social networks, there weren't differences among both genders.

c. As to using social networks for less than 3 hours/day, the females were first, where males uses such social networks for more than 6 hours/day. There weren't difference between both genders as to 3-6 hours a day.

d. There were differences between both genders as to using social networks during the week, thus males takes the lead; nonetheless, there weren't difference as to audio/video chatting, exchange of photos and video-clips over social networks.

e. There weren't differences between both genders as to accepting/rejecting friendship requests from strangers.

2. There were difference between both genders as to self-introduction, entertainment, time-killing and seeking new friendships, hence the males takes the lead, where the females takes the lead in the motives for communicating with family, friends and monitoring celebrities, art and fashion news. As to monitoring of latest developments, there are not any differences between both genders.

3. As to social positive/negative impacts, the males are more impacted negatively and the females impacted positively by using social networks.

\section{Recommendations}

Based on the findings drawn from this study, the recommendations are as follows: 
- It is imperative to encourage parents to communicate with their children who are between 9 to 12 years of age, including communication through social networks.

- It is wise that parents provide alternatives, especially for the females, in order to create a balance between the time spend on social network and other useful activities.

- It is a must that parents recognize the value of time; therefore, allocation of specific time(s) for both genders as to using social networks is required, including close monitoring of such websites/social networks used by their children.

- The cooperation and collaboration of national and international monitoring agencies is a cornerstone to protect the children (both genders) from surfing such malicious/destructive websites/social networks.

- It is educationally required that children are taught the meaning, impacts and consequences of such terms 'cyber addiction, privacy violation and giving true personal data'.

- The schools are required to hold workshops that enlightens children as to the proper use of social networks and how to make use of such educational, cultural and religious materials provided in such websites.

- Encourage the males to make use of such positive impacts found in useful websites, and to avoid such malicious websites that impacts behavior, leads to psychological-disorders, anxiety and negative-addiction resulting from excessive use of the internet.

- This study proposes more in-depth researches and studies that measures the impacts of the internet as to social behavior, e.g., the relationship between social networks usage and social deviation, the impact of family monitoring on usage patterns and the impacts of social networks on the family ties and relationships... etc.

\section{References}

Abdulraheem. (2003). The Arts of Assay's Writing \& Cognitive Processes of the Readers. Abrtrak Publishiers \& Distributors: Cairo, Egypt.

Abdulrahman Z. (2011). Educational Implications of Electronic Multimedia Usage on the Egyptian Child Culture, field study, the University of Swhajj, Egypt, 2011. Retrieved from http//goo.gl/Kwohib

Alazab, Alghamdi. (2011). Chatting on social networks (patterns, motives \& impacts). King Abdulaziz University Journal, Jeddah, Saudi Arabia, 19(1).

Alfaleeni. (1998). Communication: Means and Theories. Dar Alnahda Publishers: Cairo, Egypt.

Almawsawi. (2004). The Theory of Media. Bahrain University: Almanamah, Bahrain.

Alzayat A M. (2011). Social networks \& the future of the Arab Girls, field study, social and health impacts (Riyadh city as a role model), University of Manwfiah, Egypt, 2011, Available on www.inforcent.com.

Alzayoun A, Awdah. (2014). Social \& cultural impacts of social networks on Jordanian teenagers. Jordanian Journal, $7(2)$.

Bakheet. (2012). The Impact of Internet usage on children. Childhood \& Education Journal, University of Alexandria, 4(9), 225-256.

Brook E F., \& Dietram A S. (2002). Web vs. campus store? why students buy text books online. The journal of consumer marketing, 19(4/5), 409-423.

El Khouli M. (2013). The Most Important Negative Aspects of Using Social Networking Affecting the Family Stability in Abu Dhabi- A Pilot Study. International Journal of Engineering and Technology, 5(1), 85-90. http://dx.doi.org/10.7763/IJET.2013.V5.517

Fahmi. (1997). Egyptian Woman Motives of Global Monitoring TV Channels. Journal of Media Research, 2, 123.

Huang H. (2011). Social Media Addiction among Adolescents in Urban China: An Examination of Sociopsychological Traits, Uses and Gratifications, Academic Performance, and Social Capital, The Chinese University of Hong Kong, September 2011.

Jarar. (2011). Participation on Facebook and its relation with the trends of the Jordanian Universities students as to Family Relations. Amman, University of the Middle East.

Khader. (2009). Psychological and Social Impacts on Egypt's youths as to using social networks, study covering 
Facebook users. University of Cairo, Titled: Family, Media and Current Era Challenges.

Ktas H., Akyol M., \& Kartal H. (2014). New Media and Youth: Differences in the Use of Social Network Sites between Young Men and Women Users. Journal of Research in Gender Studies, 4(1), 721-736.

Lenhart A., \& Madden M. (2007). Teens, privacy \& online social networks: How teens manage their online identities and personal information in the age of Myspace. Pew Internet \& American life project, 2007. Retrieved from www.pewintent.org/

Makkawi E S., \& Hussein L. (1998). Communication and Contemporary Theories. Almasria Allubnania Publishers, 246-247.

Mansour, (2014). The Role of Social Networks in Fulfilling Jordan's University students' Needs. Journal of Social Sciences, 7(2).

Mazman S., \& Usluel Y. (2009). The Usage of Social Networks in Educational. World Academy of Science, Engineering and Technology, 49, 404-408.

Meier C R. (2015). Third Culture Kids and Social Media: Identity Development and Transition in the $21^{\text {st }}$ Century. Ann Arbor. United States.

Michele P H., Jocelyn S., Gillian W., \& Andrea M. (2014). A systematic review of the use and effectiveness of social media in child health. BMC Pediatrics, 14, 138. http://dx.doi.org/10.1186/1471-2431-14-138

Ministry of Communications \& Data Technology. (2014). Children's Use of Mobile Cell Phones (Global Comparison), Egypt. Retrieved from http://www.mcit.gov.eg/Ar/Publication/Publication_Summary/816

Muise A., Christofides E., \& Desmarais S. (2009). More Information than you Ever Wanted: Does Facebook Bring out the Green-Eyed Monster of Jealousy?, Cybersychology \& Behavior, 12(4), 441-4. http://dx.doi.org/10.1089/cpb.2008.0263

O'Keeffe G S. (2011). Clinical Report-The Impact of Social Media on Children, Adolescents, and Families. Pediatrics, 127(4), 800-804. http://dx.doi.org/10.1542/peds.2011-0054

Obaidat, D et al. (2014). Scientific Research. Usama Publishers, Riyadh, Saudi Arabia.

Quinn S., \& Oldmeadow J A. (2012). Brief report Is the I generation a 'we' generation? Social networking use among 9- to 13-year-olds and belonging. British Journal of Developmental Psychology, 31, 136-142. http://dx.doi.org/10.1111/bjdp.12007

Severin W, James. (1992). Communication theory origin: Methods and Uses in the Media. N.Y, Hasting house Publishers.

Sha'alan. (2013). Problems Resultant from Children's Excessive us of social networks \& Proposed Solutions. Tanta University: 422-476, Egypt. Retrieved from http://search.mandumah.com/Record/471197

Shalynn W., Bethany C., \& Michael M. (2013). Underage Children and Social Networking. Journal of Research on Technology in Education, 45(3), 249-262. http://dx.doi.org/10.1080/15391523.2013.10782605

Simonpietri S. (2011). Social Media: Current Trends Among Children and Their Parents and Implications Regarding Interpersonal Communication, Magna Cum Laude Thesis Candidate, May 5, 2011, Professor Jeremy Rose COMM, 4471. Retrieved Friday:30, 10, 2015 from http://purl.umn.edul109501. University of Minnesota, paper research, USA, 2011.

Titto V., \& Nivedhitha D. (2014). Indian Teenagers and their Family Relations in the Social Networking Era. Rajagiri Journal of Social Development, 6(1), 21-31.

Wenner L A. (2013). The Nature of News Gratification. In: P. Palmgreen, L.A. Wenner, \& K.E. Rosengreen (eds.), Media Research. London: Beverly Hills, Sage Publications. Retrieved September 2013 from http://www.go-gulf.com/blog/ Internet Usage in The Middle East - Statistics and Trends [Infographic].

Wijesundara T R. (2014). Motives and Usage Patterns of Social Networking Sites: Exploring Cultural Differences Between United States \& Sri Lanka. Canadian Social Science, 10(6), 176-185. 